Journal of Health, Education and Literacy (J-Healt)

https://ojs.unsulbar.ac.id/index.php/j-healt/

\title{
Penerapan Asuhan Keperawatan Pada Pasien Dalam Gastritis Dalam Pemenuhan Kebutuhan Nutrisi
}

Application Of Nursing Assistance In Patients With Gastritis Impaired Fulfillment Needs Nutrition

\author{
Harmawati
}

Prodi DIII Keperawatan Fakultas Kedokteran Dan Ilmu Kesehatan Unismuh Makassar

\section{Keywords :}

Gastritis, Lack of Nutrition

\section{Kontak :}

Harmawati

Email :

harmamusliminfira@yahoo.co.Id

Prodi DIII Keperawatan Fakultas

Kedokteran Dan Ilmu Kesehatan

Unismuh Makassar

DOI : https://doi.org/10.15294/

kemas.v14i3.1562

\section{(C)2020J-Healt}

ini adalah artikel dengan akses terbuka dibawah licenci CC BY-NC-4.0

https://creativecommons.org/licenses/by-nc/4.0/

\begin{abstract}
Abstrak
Gastritis atau secara umum dikenal dengan istilah sakit "maag" atau ulu hati adalah peradangan pada dinding lambung terutama pada selaput lendir lambung. Penyakit ini sering dijumpai dengan rasa mual dan muntah, nyeri, perdarahan, rasa lemah, nafsu makan menurun atau sakit kepala. Tujuan penelitian ini yaitu Menerapkan Asuhan Keperawatan Pada Pasien Nn. M dengan Gastritis dalam pemenuhan kebutuhan Nutrisi. Metode Menggunakan tehnik wawancara, observasi dan pengamatan. Setelah dilakukan tindakan keperawatan selama 3 hari pada pasien Nn.M dengan masalah perubahan nutrisi kurang dari kebutuhan yang berhubungan dengan intake oral yang tidak adekuat telah teratasi. Berdasarkan dari hasil tindakan yang dilakukan pada Nn. M dapat disimpulkan bahwa masalah perubahan nutrisi kurang dari kebutuhan yang berhubungan dengan intake oral yang tidak adekuat dapat teratasi dengan baik. Diharapkan kepada perawat agar kiranya melakukan asuhan keperawatan sesuai keluhan klien
\end{abstract}

\section{Abstract}

Gastritis or commonly known as "ulcer" or gastrointestinal pain is inflammation of the stomach wall especially in the lining of the stomach liver. The disease is often found with nausea and vomiting, pain, bleeding, weakness, decreased appetite or headache. Objectives is Applying Nursing Care In Patients Nn. M with Gastritis in the fulfillment of Nutrition needs. Methods Using interview techniques, observation and observation. After 3 days of nursing action in Nn. M patients with nutritional change problems less than those associated with inadequate oral intake have been resolved. Based on the results of actions taken on Ms. M it can be concluded that the problem of nutrient change is less than the need associated with inadequate oral intake can be resolved well. It is expected that the nurse should perform nursing care according to the client's complaint 


\section{PENDAHULUAN}

Gastritis atau secara umum dikenal dengan istilah sakit "maag" atau ulu hati adalah peradangan pada dinding lambung terutama pada selaput lendir lambung. Penyakit ini sering dijumpai dengan rasa mual dan muntah, nyeri, perdarahan, rasa lemah, nafsu makanmenurun atau sakit kepala. (Rahmi Kurni,2011)

Gastritis biasanya dianggap sebagai suatu hal yang remeh namun gastritis merupakan awal dari sebuah penyakit yang dapat meyusahkan kita. Sebagian besar onset penyakit gastritis yang terjadi di Negara maju mengenai usia tua. Hal yang berbeda dengan Negara berkembang yang onset penyakitnya mengenai usia dini. Angka kejadian gastritis pada beberapa daerah di Indonesia cukup tinggi prevalasinya yaitu 274,396 kasus dari 283,452,952 jiwa penduduk. (Anonim,2011)

Dari data Dinas Kesehatan Kota Makassar kasus gastritis dari tahun 2009 sampai 2011 terus mengalami peningkatan. Dimana pada tahun 2009, kasus gastritis yaitu 36.766 penderita. Kemudian tahun 2010 sebanyak 43.547 penderita, dan tahun 2011 semakin meningkat yaitu sebanyak 46.939 pasien. Gastritis termasuk 10 besar penyakit utama di Makassar dengan jumlah penderita terbanyak. (Profil Kesehatan Dinas Kesehatan Kota Makassar, Tahun 2012)

\section{METODE}

Desain studi kasus yang dilaksanakan adalah penelitian deskriptif. Penelitian deskriptif merupakan penelitian dengan melalui pengamatan ( Observasi) baik secara langsung maupun tidak langsung. Studi kasus dilakukan di wilayah Puskesmas Makkasau pada tanggal 2 - 5 Agustus 2019

\section{HASIL}

Pasien yang bernama Nn. M, umur 21 tahun, tempat tanggal lahir Enrekang 03 Juni 1996, Alamat Jln. Gunung Merapi Lorong 07 No.58, pendidikan SMA, Agama Islam, Suku Makassar, informan pada pasien dan keluarga, pengkajian dilakukan pada hari/tanggal Rabu, 02 Agustus 2019.

Keluhan utama "nyeri ulu hati disertai dengan mual muntah", klien mengatakan nyerinya tembus kebelakang dan terasa tertusuk-tusuk, klien mengeluh nyeri ulu hati yang disertai mual muntah beberapa hari yang lalu. Klien mengatakan bahwa klien dilarikan ke Puskesmas karena mengalami nyeri ulu hati yang disertai mual muntah, Nampak bibir kering, konjungtiva pucat, klien mengatakan pernah dirawat di Rs Pelamonia Makassar dengan sakit yang sama dan pernah operasi dengan penyakit tumor telinga,klien mengatakan kurang nafsu makan.TB: $160 \mathrm{~cm}$, BB sebelum sakit $48 \mathrm{~kg}$, BB setelah sakit 45 $\mathrm{kg}$, TTV : TD : 90/60 mmHg, Pernafasan 22x/i, Nadi : $83 x / I$, Suhu : 36,5 derajat celcius.

\section{PEMBAHASAN}

Pengkajian menurut ( Pelapina Heriana, 2014) dengan gangguan kebutuhan nutrisi adalah adanya mual muntah, konjungtiva pucat, anoreksia, kehilangan BB, dan sebagainya.

Sedangkan data hasil studi kasus yang diperoleh peneliti pada saat melakukan penelitian adalah adanya nyeri pada ulu hati yang dirasakan seperti tertusuk-tusuk yang disertai dengan mual dan muntah, bibir kering, dan konjungtiva pucat.

Dengan demikian antara teori dan kasus ditemukan adanya kesenjangan antara teori dan kasus dimana ada data yang tidak terdapat didalam kasus tapi ada dalam teori.

Perubahan Nutrisi Kurang dari Kebutuhan yang berhubungan dengan Intake Oral yang tidak Adekuat. Diagnosa ini diangkat berdasarkan data yang ditemukan pada kasus, yaitu Data Subjektif : Klien mengatakan nyeri 
ulu hati disertai dengan mual muntah, klien mengeluh nyeri ulu hati yang disertai mual muntah beberapa hari yang lalu, klien mengatakan kurang nafsu makan. Data Objektif : bibir kering, konjungtiva pucat, TB: $160 \mathrm{~cm}, \mathrm{BB}$ sebelum sakit $48 \mathrm{~kg}$, BB setelah sakit $45 \mathrm{~kg}$.

Penulis akan membahas rencana keperawatan sesuai dengan prioritas masalah pada pasien. Rencana keperawatan dengan tujuan setelah dilakukan tindakan keperawatan selama 3 hari kebutuhan nutrisi terpenuhi dengan kriteria hasil : Pasien mengungkapkan adanya peningkatan selera makan, Pasien akan mengungkapkan tidak ada mual muntah, konjungtiva tidak anemis, serta adanya peningkatan nafsu makan .

Intervensi dibuat sesuai dengan diagnose keperawatan antara lain : Kaji pola makan pasien, Rasional : mengidentifikasi kebutuhan nutrisi khusus, Kaji adanya anoreksia, mual, muntah, Rasional : dapat mempengaruhi pilihan diet, Timbang BB setiap hari, Rasional : berguna dalam mengukur keefektifan nutrisi, Anjurkan pasien untuk beristirahat, Rasional : membantu menghemat energy khususnya bila kebutuhan metabolik meningkat, Anjurkan pasien makan porsi kecil tetapi sering, Rasional : Memaksimalkan pemenuhan kebutuhan nutrisi dan menurunkan iritasi gaster, Observasi TTV, Rasional : Mengetahui perkembangan klien.

Pada tahap ini tidak terdapat adanya kesenjangan antara teori dan hasil studi kasus karena intervensi yang terdapat dalam teori sama dengan intervensi yang disusun pada hasil studi kasus.

Implementasi dilakukan berdasarkan intervensi yang telah disusun dari diagnosa yang ditegakkan dalam studi kasus. Semua perencanaaan terlaksana dengan baik tanpa ada kendala karena adanya dukungan dari klien serta keluarga klien tersebut dalam mengaplikasikan tindakan tersebut.

\section{KESIMPULAN}

Diagnosa keperawatan utama yang ditegakkan oleh penulis pada Nn. M adalah "Perubahan Nutrisi Kurang dari Kebutuhan yang berhubungan dengan Intake Oral yang tidak Adekuat".

\section{SARAN}

Diharapkan kepada seluruh pengembang dan technologi keperawatan agar semua pasien Gastritis di Wilayah Kerja Puskesmas Makkasau Makassar diberikan penyuluhan dan konseling tentang program pencegahan penyakit Gastritis.

\section{UCAPAN TERIMA KASIH}

Prodi DIII Keperawatan Fakultas Kedokteran dan Ilmu Kesehatan, Kepala Puskesmas dan staf pengelola Puskesmas Makkasau

\section{DAFTAR PUSTAKA}

Herdman, T. H. (2016). Diagnosis Keperawatan Definisi Keperawatan 2012-2014. Jakarta: EGC.

Hidayat, A. A. (2012). Buku Ajar Kebutuhan Dasar Manusia; Pendekatan Kurikulum

Berbasis Kompetensi. Surabaya: Health Books Publishing.

Medikal Bedah Untuk Mahasiswa. Yogyakarta: DIVA Press.

M. D., Donna Jackson, \& J. K. (2007). Keperawatan Medikal Bedah. Yogyakarta: Rapha Publishing.

endi, M. C., \& M. T. (2012). Asuhan Keperawatan Medikal Bedah dan Penyakit Dalam. Yogyakarta: Nuha Medika.

Saputra, D. L. (2014). Buku Ajar Kebutuhan Dasar Manusia. Tangerang Selatan: BINARUPA AKSARA Publisher.

Selviana, B. Y. (2015). Effect Of Coffe And Stress With The Incidence Of Gastritis. 
Siswanto, Susila, \& Suyanto. (2012).

Metodologi Penelitian Kesehatan dan Kedokteran. EGC: Jakarta.

Wijaya, A. S., \& Putri, Y. M. (2013). $K M B$ Keperawatan Medikal Bedah Keperawatan Dewasa Teori dan Cintoh Askep. Yogyakarta: Nuha Medika. 